$\xi=$

\title{
Anomaly technique for expression the Indian Ocean Dipole in South Java Sea
}

\author{
Aida Sartimbul ${ }^{1,2 *}$, Erfan Rohadi ${ }^{3}$, Mochammad Firdaus Ali ${ }^{4}$, Zulfan Khaidar ${ }^{1}$ \\ ${ }^{1}$ Faculty of Fisheries and Marine Science, Brawijaya University, Malang, Indonesia \\ ${ }^{2}$ Marine Resources Exploration and Management (MEXMA) Research Group, Faculty of Fisheries and Marine Science, Brawijaya Uni- \\ versity, Malang, Indonesia \\ ${ }^{3}$ Information Management, State Polytechnic of Malang, Indonesia \\ ${ }^{4}$ Electrical Engineering Department, State Polytechnic of Malang, Indonesia \\ *Corresponding author E-mail: aida@ub.ac.id
}

\begin{abstract}
The longer period of time series of anomaly data was usually used to express the climatic phenomena. Even it is common, however, there were limited study discusses how powerful anomaly technique for understanding the climatic phenomena that occur in the period of time. The objective of this study is to understand the nature of anomaly, to identify an unusual fluctuation of data, and to detect the climate change impact to the Sea Surface Temperature (SST). The eleven years satellite Aqua Modis data and Dipole Mode Index were applied to this study. The raw data were averaged and removed seasonal trend using anomaly technique and then plotted to both MS Excel and Surfer ver. 6 . The result shows that the monthly average of SST was indicated a seasonal/ sinusoidal pattern. Furthermore, anomaly analysis provides an unusual SST trend that has a direct impact on the climatic phenomenon as Indian Ocean Dipole. It is suggested that an anomaly technique may provide a good tool for expression unusual phenomena due to climate change.
\end{abstract}

Keywords: Anomaly; Average; Climate change, SST; Time series

\section{Introduction}

Oceanographic phenomena vary in space and time scale. The smallest phenomena such as bubbles, capillary waves, even El Nino Southern Oscillation (ENSO), Indian Ocean Dipole (IOD) and thermohaline circulation and Milankovitch, occur from the narrowest $(\mathrm{mm})$ to the widest (thousands of $\mathrm{km}$ ) of space oceans and also require the shortest time $(0.001 \mathrm{sec}$.) to the longest (thousands of years) (1). Data availability and analytical methods are important in oceanographic studies. Creativity in analyzing data, especially serial data is very important in determining the results and interpretation of the data so as to provide useful information in studying a phenomenon in oceanography.

The abundance of data due to the development of modern physics oceanographic instruments such as CTDs, current meters, satellite instruments capable of measuring many samples per unit of seconds, means that the average analysis is more utilized than individual analysis. This average analysis is generally plotted on time series charts based on raw data or just average, so seasonal trends are still visible. This method is not enough to explain the existence of deviation or anomalies in the time series graph.

One method of approach in analyzing oceanographic phenomena on a relatively long-time scale is the anomaly method. According to (1), an anomaly is a difference between a measured value and a mean value. This anomaly method is commonly used not only in the fields of oceanography, but also in the fields of meteorology and climate, such as study conducted by (2); (3), (4); (5), etc. However, in previous studies the anomaly method was not dis- cussed in detail, even though this method is very important in looking the peculiarities of a time series data. Therefore, this article was compiled.

\section{Material and Methods}

\subsection{Material}

This research was carried out in the South Java Sea at $7-14^{\circ} \mathrm{S}$ and $103-115^{\circ} \mathrm{E}$ (Figure 1). The South Java Sea are areas that are directly adjacent to the Indian Ocean and are potential fishing grounds due to the presence of upwelling in these waters. The dynamics of the waters of the South Java are strongly influenced by global climate phenomena such as the Indian Ocean Dipole as explained by (2), (4) and (5).

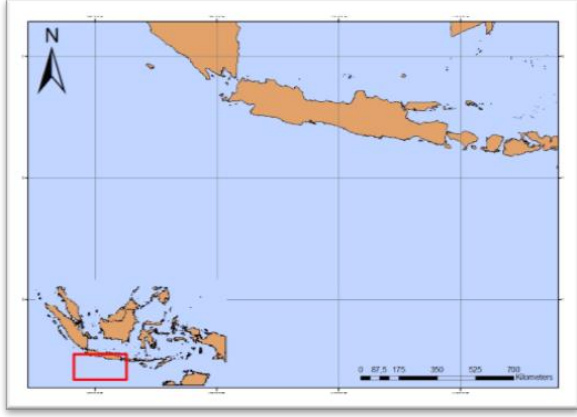

Fig.1. Map of study area at South Java Sea. Copyright $\odot 2018$ Authors. This is an open access article distributed under the Creative Commons Attribution License, which permits unrestricted use, distribution, and reproduction in any medium, provided the original work is properly cited. 
A total of 11 (eleven) years of Sea Surface Temperature (SST) data with monthly intervals from Satellite Aqua-MODIS level 3 data obtained from the official website oceancolor.gsfc.nasa.gov. became the main data in this study. While the additional data is the data for climate change indexes such as the Indian Ocean Dipole or the Dipole Mode Index obtained from jamstec.go.jp/frsgc/research/d1/iod/iod/dipole_mode_index.html.

Indian Ocean Dipole is an El Niňo like phenomenon that occurs in Indian Ocean. It is another important manifestation of the tropical air-sea interaction (6)(7)(8). Positive IOD is indicated warm phase of SST in Africa and cold phase of SST in South Indonesia, or vice versa (6). Like the Pacific ENSO, the evolution of the IOD is strongly locked to the annual cycle. In active years, cold SST anomalies off Java and Sumatra typically develop in June to August and peak in September to October, while warm SST anomalies in the western Indian Ocean occur later (9). The Dipole Mode Index (DMI) is an index that expresses the IOD. It is defined as the sea surface temperature anomaly (SSTA) difference between the tropical western Indian Ocean $\left(50^{\circ} \mathrm{E}-70^{\circ} \mathrm{E}, 10^{\circ} \mathrm{S}-10^{\circ} \mathrm{N}\right)$. Both El Nino and IOD also explain most of the tropical Indian Ocean variability due to their contribution about $30 \%$ and $12 \%$ of the tropical Indian Ocean, respectively (7).

\subsection{Methods}

Raw data and seasonal mean were plotted in time series graph to look at the trend. Data processing usually were started with averages over many samples, for examples, over 1 second or some other time interval. For this case monthly average is applied. The samples mean $\bar{x}$ of a data set $x$ that has been measured $N$ equally spaced times is

$\bar{x}=\frac{1}{N} \sum_{i=1}^{N} x_{i}$

With the increasing number of observations, Eq. (1) approaches the true mean if there is no external source of bias error.

An anomaly is the difference between a measured value and the mean value (1):

$x^{\prime}=x-\bar{x}$

The quantity of $x^{\prime}$ is also often referred to as a deviation from the mean; it is also referred to as an anomaly. Depending on the study, it might also be common to remove a seasonal cycle from the original data set by computing monthly or seasonal means rather than the overall mean, and then displaying the anomalies relative to the monthly or seasonal means (1).

Both average and anomaly analysis were plotting in time series graph of MS Excel 10. Furthermore, anomaly data were plotted at 2D map using Software Surfer 6.

\section{Results and Discussion}

The following paragraph will discuss about the strengthen and weakness of raw data and anomaly data for oceanographic data expression.

\subsection{The time series of the raw data of Sea Surface Tempera- ture (SST)}

Time series of average data Sea Surface Temperature (SST) were plotted in Figure 2. The sea surface temperature showed seasonal variation: the higher SST trend occurred in Northwest monsoon (Dec, Jan, and Feb) and lower SST trend in Southeast monsoon, furthermore moderate SST found in between both monsoons. By only plotting the average data, ones only found the sinusoidal pattern in time series of SST average data. Therefore, it is not easy to identify the climate change phenomenon only used Figure 2.

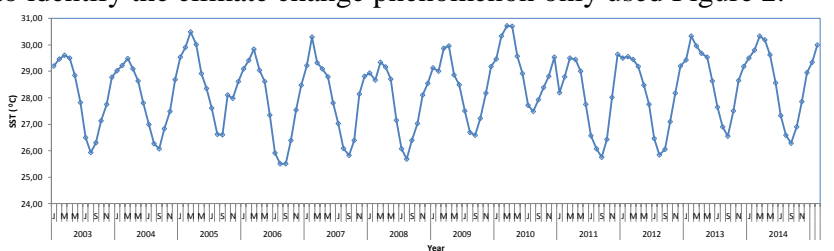

Fig.2. Time series of monthly average data of Sea Surface Temperature at South Java Water. Seasonal variation is common using time series of raw data or average data.

The anomaly analysis approach provides information of irregular trend within period of study by removing seasonal cycle as mention in chapter 2, material and method. Figure 3 represented the time series of both raw data of SST and its anomalies. By using anomaly data, ones could find the anomalous or extreme fluctuation of SST trend, however nor for average data. The time series of SST anomaly presented positive and negative fluctuations at ranged between -1 (in 2006) to $+1.5^{\circ} \mathrm{C}$ (in 2010), respectively. The anomalous or extreme SST both positive and negative will tell something about the unusual phenomenon both in ocean and atmosphere as a couple system. Further analysis will tell about SST anomaly by using Surfer ver. 6 and moreover their correlation with the global climate change by applying Indian Ocean Dipole Index.

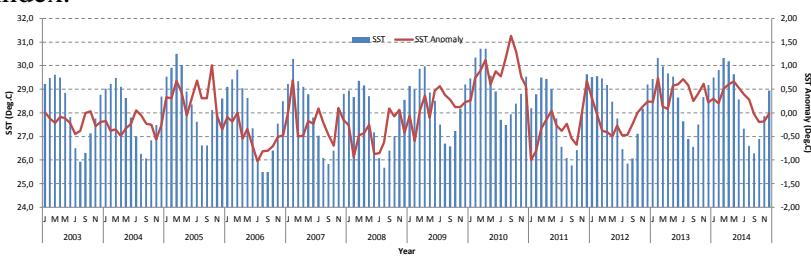

Fig. 3. Time series monthly average of SST data (blue bar) and SST anomaly (red-solid line).

\subsection{Time series of SST anomaly and Indian Ocean Dipole (IOD)}

In order to understand SST anomaly well, SST anomaly data were also plotted in 2D map of Surfer as shown in Figure 4. Based on Figure 4, SST anomaly well indicated the SST decrease or increase compared eleven years-time series data. By using anomaly technique, the anomaly or deviation of eleven-years data are able to well identified. Blue-violet colour indicated about 0.5 to $1.0^{\circ} \mathrm{C}$ lower below SST average during eleven years. While, yellow-red colour showed about 0.5 to $1.5^{\circ} \mathrm{C}$ SST increasing above eleven years average. 


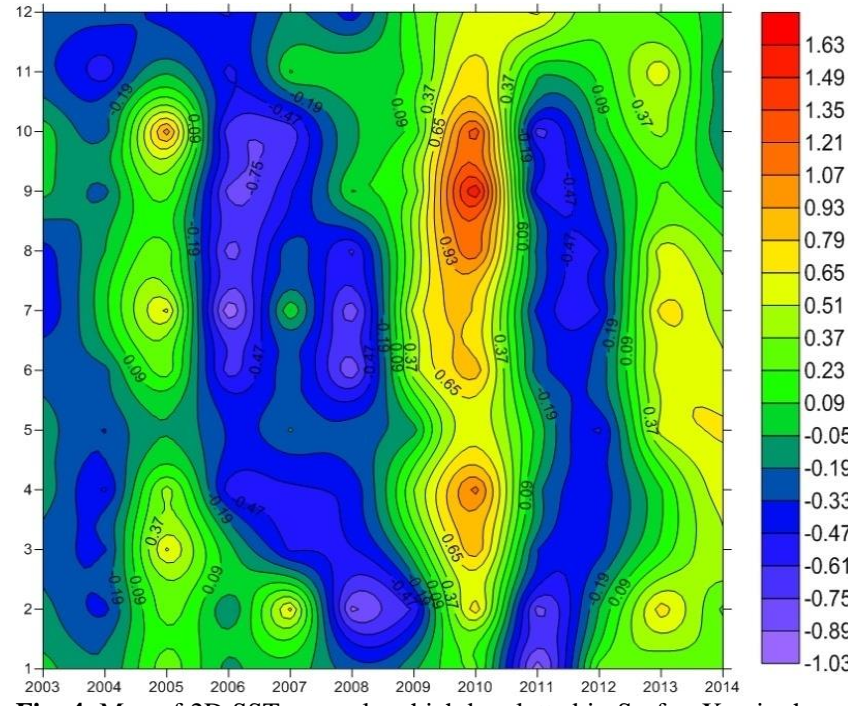

Fig. 4. Map of 2D SST anomaly which be plotted in Surfer. X axis shows the year (2003-2014), while Y axis indicates the month (Jan-Dec). Unit of SST anomaly is ${ }^{\circ} \mathrm{C}$.

Lower SST anomaly profoundly occurred in 2006, while higher one found in 2010. Both years were indicated climatic phenomena events as El Niňo (2) and La Niňa, respectively (4)(5)(9). El Nino is a phenomenon characterized by increasing sea surface temperatures in the eastern and central Pacific caused by the weakening of wind trade at intervals of 2 or 7 years. El Nino has an impact on the occurrence of droughts in the western Pacific region including Indonesia. Whereas La Nina is a reverse phenomenon, and has an impact on prolonged rainfall (9).

The El Nino and La Nina phenomena as known as El Nino Southern Oscillation (ENSO) is identical to the phenomena that occur in the Pacific region. An El Nino-like phenomenon that occurs in Indian Ocean is known as the Indian Ocean Dipole.

Those El Niňo and La Niňa are also coincided with Indian Ocean Dipole (IOD) positive (+) and negative (-), e.g. in 2006 and 2010.

To understand Indian Ocean Dipole (IOD) phenomenon, SST anomaly were plotted together with IOD index, Dipole Mode Index (DMI) as shown at Figure 5.

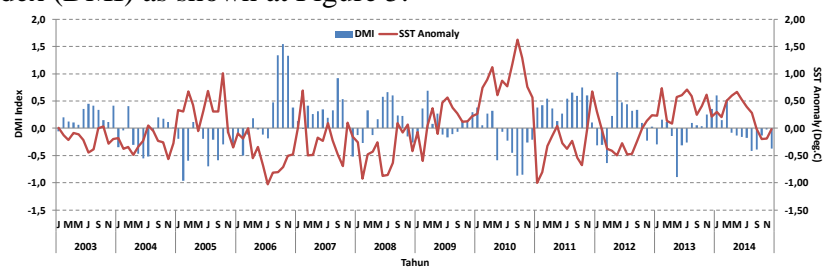

Fig.5. Time series of DMI and SST anomalies. Blue bar shows the time series of DMI and red solid line indicates the time series of SST anomalies.

During IOD (+) (2006) there were more intensive upwelling in South Java as indicated by lower SST (reached $-1.0^{\circ} \mathrm{C}$ ), and vice versa for IOD (-) (2010) SST remain higher (reached $+1.5^{\circ} \mathrm{C}$ ) due to lack of upwelling as mentioned by (2) (4) and (5).

The ENSO and IOD phenomena are intensifying with the recent increase in global warming (10). However, increase in the frequency of extreme ENSO events is largely independent of increased frequency of extreme positive Indian Ocean Dipole events (10), but the sequence of climate extremes similar to what the world experienced during ENSO 1997-1999, is projected to increase markedly, from one in 187 years to one in 48 years; during these two years, an extreme positive Indian Ocean Dipole preceded an extreme El Niño, and was then followed by an extreme La Niña (3).
Time series data with a long period of time may provide information on climate change and can even be used as a tool to predict climate change.

\section{Conclusion}

An anomaly technique is easy way to show unusual phenomenon for long period of time series data. Without using anomaly analysis, we will face the seasonal pattern that expressed a sinusoidal shape as usually experiences with raw data. An Anomaly analysis was also match well with climatic index, therefore they are suitable to be plotted together and be able to express the possible relation between SST anomaly and climate change phenomenon such as Indian Ocean Dipole. It is suggested that an anomaly technique will provide a basic tool for further analysis not only for oceanography, but also for meteorology, climate, and etc.

\section{Acknowledgement}

We thank the National Oceanic and Atmospheric Administration (NOAA) and Japan Agency for Marine-Earth Science and Technology (JAMSTEC) for the production and preparing Satellite SST data and Dipole Mode Index, respectively. Anonymous reviewers for their valuable comments. This research was supported by Ministry of Research and Higher Education (KEMENRISTEK DIKTI) of Republic of Indonesia No. 137/SP2H/LT/DRPM/III/2016. This paper was presented at the International Conference on Enhanced Computer Research Engineering, and Advanced Multimedia in Jogjakarta, Indonesia in 2018.

\section{References}

[1] Talley LD, Pickard GL, Emery WJ, Swift JH, Descriptive Physical Oceanography: An Introduction, Elsevier, (2011), pp:152-153.

[2] Sartimbul A, Nakata H, Rohadi E, Yusuf B, Kadarisman HP, "Variations in chlorophyll-a concentration and the impact on Sardinella lemuru catches in Bali Strait, Indonesia", Progress in Oceanography, Vol.87, (2010), 168-174, available online: www.elsevier.com/locate/pocean. Doi:10.1016/jpocean.2010.09.002.

[3] Chai W, Santoso A, Wang G, Yeh SW, An SI, Cobb KM, Collins M, Guilyardi E, Jin FF, Kug JS, Lengaigne M, McPhaden MJ, Takahashi K, Timmermaan A, Vecchi G, Watanabe M, Wu L, "ENSO and greenhouse warming", Nature Climate Change, (2015), pp.849-859, available online: www.nature.com/natureclimate change. DOI: 10.1038/NCLIMATE2743

[4] Arleston J, Yuli E, Sartimbul A, "Dynamics of Indian Scad Fish (Decapterus spp.) cathing linked with temperature variation due to ENSO phenomenon in Bali Strait", International Journal of ChemTech Research. Vol.9, No.9, (2016), pp.237-246, http://www. Sphinxsai.com.

[5] Sartimbul A, Rohadi E, Yona D, Yuli HE, Sambah AB, Arleston J, "Change in species composition and its implication on climate variation in Bali Strait: case study in 2006 and 2010", International Journal on Survey in Fisheries Science. Vol.4, No.2, (2018), pp.3846.

[6] Saji NH, Goswami BN, Vinayachandran PN.,Yamagata T. "A dipole mode in the Tropical Indian Ocean”, Nature. Vol.401, (1999), pp.360-363

[7] Webster PJ, More AM, Loschnigg JP, Leban RR, "Coupled oceanatmosphere dynamics in the Indian Ocean during 1997-98". Nature, Vol.403, (1999), pp.356-360.

[8] Qu T, Du Y, Strachan J, Meyers G, Slingo J, "Sea Surface Temperature and its variability in the Indonesia region". Oceanography. Vol.18, No.4, (2005), pp.50-61.

[9] NOAA, Cold and Warm episodes by season. http://origin.cpc.ncep.noaa.gov/products/analysis_monitoring/ensos tuff/ONI_v5.php. Accessed online on on November $15^{\text {th }}, 2018$.

[10] Cai, W. et al. Increased frequency of extreme Indian Ocean Dipole events due to greenhouse warming. Nature 510, 254-258 (2014). 